\title{
Investigation on the Breakdown Characteristics of Different Types of Lightning Rods
}

\author{
Noor Azlinda Ahmad*, Rosniza Zainal and Zuraimy Adzis \\ Institute of High Voltage \& High Current, Faculty of Electrical Engineering, Universiti Teknologi Malaysia, 81310 UTM \\ Skudai, Johor, Malaysia.
}

"Corresponding author: noorazlinda@utm.my

\begin{abstract}
This paper investigates the voltage breakdown characteristics of three types of lightning rods - blunt, sharp and flat. The objectives of this study are to determine the voltage breakdown characteristics of various types of lightning rods and to obtain the striking distance of each rod. A series of experiments were conducted in the high voltage laboratory consisting of individual testing rod, competitive testing rod and also horizontal distance changing. All three types of rods have been tested in each experiment in order to obtain a comprehensive result. The blunt rod has been proven as the best strike receptor in comparison to sharp and flat rod. This is because breakdown voltage for blunt rod is much lower $(199 \mathrm{kV})$ than that of flat and sharp rod. Therefore, replacement of widely used sharp rod with the blunt one should be considered in order to provide better protection for buildings from lightning activities
\end{abstract}

Keywords: air terminal, lightning, lightning protection, lightning rod, striking distance

(C) 2018 Penerbit UTM Press. All rights reserved

Article History: received 5 June 2017; accepted 18 August 2018; published 29 August 2018.

\section{INTRODUCTION}

Lightning strike is the most powerful and dangerous electrostatic discharge in nature. With the conductive air, charges in the cloud can be transferred to the ground and hence lightning strike occurs. Lightning strike is a major cause of destruction of power electric system and many other electrical equipment as well as fatalities of human beings. Because of that reason, controlling and directing the energy of lightning to protect humans, buildings and equipment is very critical and is of a main concern of electrical engineers [1].

Basically, there are three different parts of external lightning protection systems for buildings, which consists of lightning air terminal (lightning rod, which is typically installed on top of buildings or structures), down conductor and earthing systems. All three parts are crucial and extra precaution is needed during the installation to ensure the efficiency of protection system and safety of buildings to be protected. A network of lightning rods will intercept the lightning event and direct it to the conductor wire. Then the conductors confine and direct the lightning event towards eventual dissipation into earth. Finally, the grounding system of the lightning protection system is designed to transfer the lightning current from the conductor into earth.

This study will focus on the external protection component that is lightning rod. There are two types of lightning rod design; conventional and non-conventional (ESE or Early Streamer Emission). Majority of lightning rod in use today are of the traditional Franklin design. The fundamental principle used in Franklin-type lightning protection systems is to provide a sufficiently low impedance path for the lightning to travel through to reach ground without damaging the building [2]. Lightning rod requires a connection to earth to perform its protective function. The main attribute of all lightning rods is that they are highly conductive. Typically, copper and its alloys are the most common materials used as lightning rod [3]. In recent study, a metal layer was set to surround lightning rod for shielding [4] in order to reduce electromagnetic field radiation from lightning. It is shown that the metal layer affects the distribution laws of vertical electric field above the ground fiercely.

There are sev eral types of lightning rods such as sharppointed tip, blunt tip, standard tip and many more in use nowadays. Sharp tipped rods are widely used all over the world, however research done previously found that moderately blunt tipped is the most effective lightning strike receptor in comparison to the sharp one $[5,6]$. A group of researchers did an experiment with several sharp and blunt rods with different diameter of tip [7]. Each lightning rods were set up with the same height. The lightning rods were mounted on the 6 meter tall poles and separated 6 meter with each other. Their result showed that none of the sharp rods were struck by lightning. Also, there was no lightning strikes on the smallest and biggest diameter of blunt tipped. Most of the time, lightning strike the blunt tipped with the moderate diameter which is about $19 \mathrm{~mm}$. Most recently, an investigation of attachment process of downward lightning flashes to residential building had been carried out by [8] using a high-speed video camera. Based on their study, parameters like striking distance and connecting leaders speed, largely used in lightning attachment models and in lightning protection standards, are revealed.

On the other hand, a non-conventional lightning protection system known as ESE (Early Streamer 
Emission) had been claimed by their manufacturer to be more effective than sharp pointed lightning rods. Nevertheless, these system do not fucntion as it was claimed. The same goes with the Charge Transfer System (CTS) too. They claimed that the CTS can eliminate the lightning strike but the facts is the CTS can only reduce damage from lightning strike [7]. Another nonconventional air terminal which uses the teory of corona discharge phenomenon is Bipolar Conventional Air Terminal (BCAT) developed by OMNI LPS [9]. It was reported that BCAT has proved its efficacy at a number of sites where it is installed, as well as through related papers published in IEEE [10-12]. Also, it is further verified that BCAT is effective at discharge than existing air terminals for lightning prevention [13]. Since many of these claims were made by the manufacturer, therefore further investigation is However, thourough investigation is needed before one can jump into conclusion on the effectiveness of BCAT.

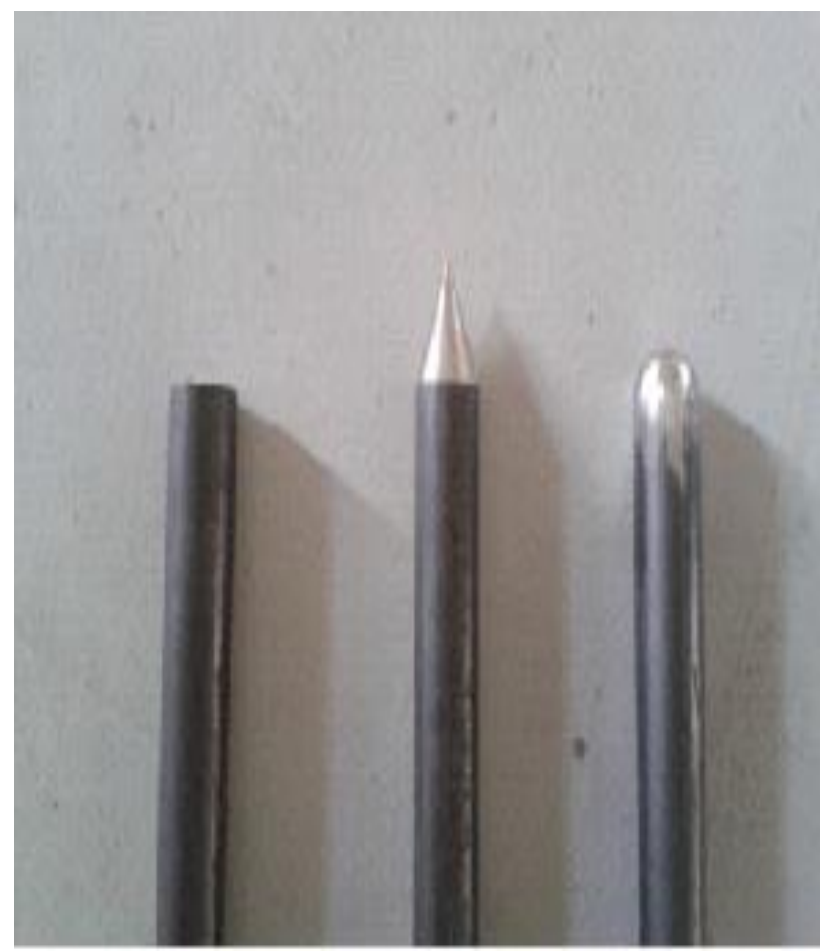

Figure 1. Different types of lightning rod, from left: flat, sharp and blunt surface

\section{EXPERIMENT}

In order to investigate the breakdown characteristics of different types of lightning rods, three different experimental set up had been designed which include:-

- Breakdown voltage of Individual lightning rod

- Competitive rod test of lightning strike

- Striking distance test

Experiment was held at Institute of High Voltage \& High Current (IVAT) Laboratory in Universiti Teknologi Malaysia with the temperature and pressure in the range of 28 - $29.5^{\circ} \mathrm{C}$ and 1015 - $1016 \mathrm{Mbar}$, respectively.

\subsection{Breakdown voltage of individual lightning rod}

The experimental setup to determine breakdown voltage for individual lightning rod is illustrated in Figure 2. The objective of this test is to dete rmine the breakdown voltage of each lightning rod. The lightning rod was set up at $1.0 \mathrm{~m}$ height above ground. A gap of $0.2 \mathrm{~m}$ between lightning rod and impulse conductor was set. A $250 \mathrm{kV}$ impulse was injected ten times to the impulse conductor via High Voltage Impulse Generator and breakdown voltage was recorded using High Resolution Impulse Analyzing System (HiAS 743). Similar procedures were repeated with other types of lightning rod.

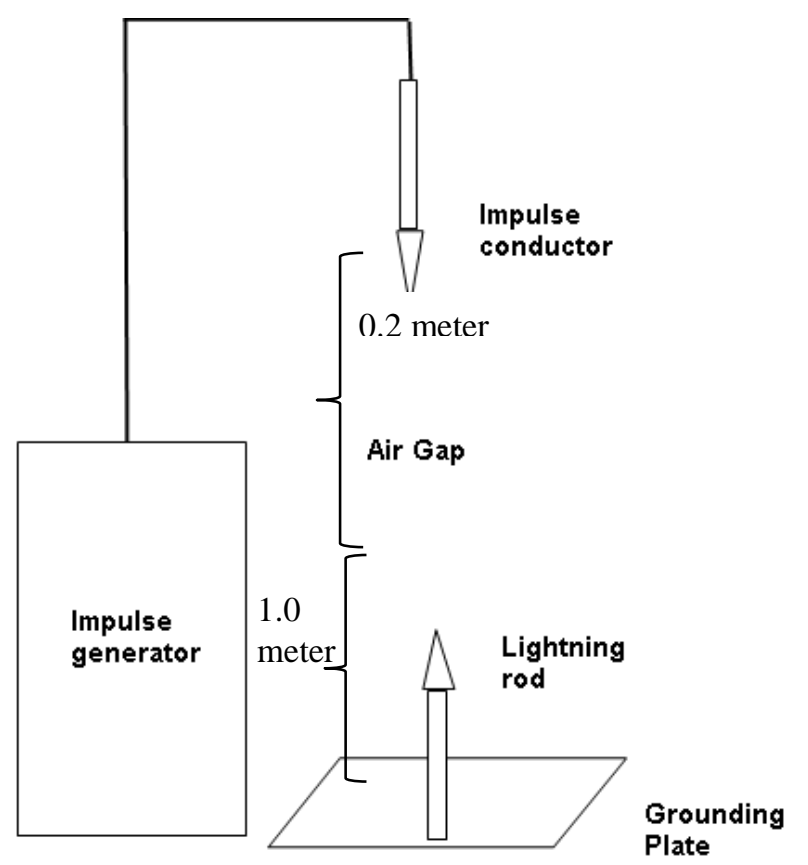

Figure 2. Experimental set up of individual lightning rod breakdown voltage

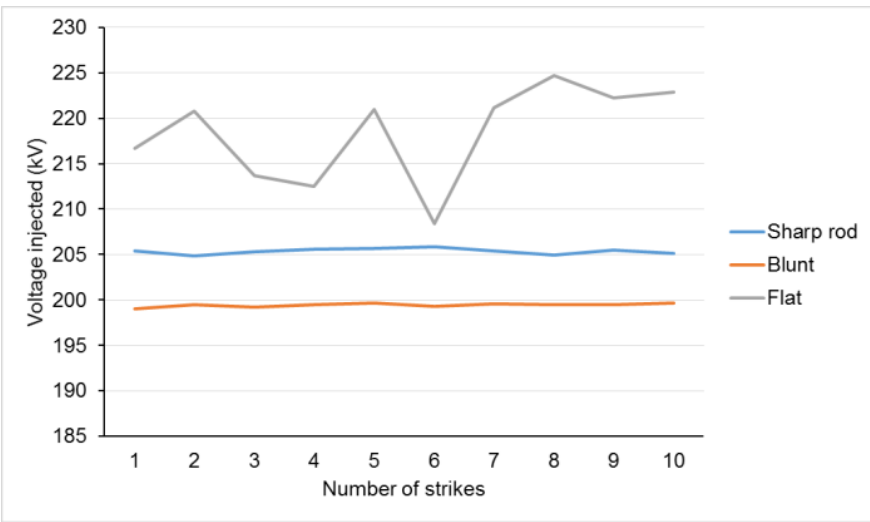

Figure 3. A graph showing various breakdown voltage for different types of lightning rod.

\subsection{Competitive rod test of lightning strike}

In this test, lightning rods were arranged $0.2 \mathrm{~m}$ apart from each other. Three different pairs of lightning rods were selected that are blunt - flat, sharp - flat and blunt - sharp. The distance between lightning rod and impulse conductor is also set to $0.2 \mathrm{~m}$. A voltage of $220 \mathrm{kV}$ was applied to every pair of lightning rod. Ten sets of data were recorded. Similar procedures were repeated with other pair of rods. 
Experimental set up of competitive test is as shown in Figure 4.

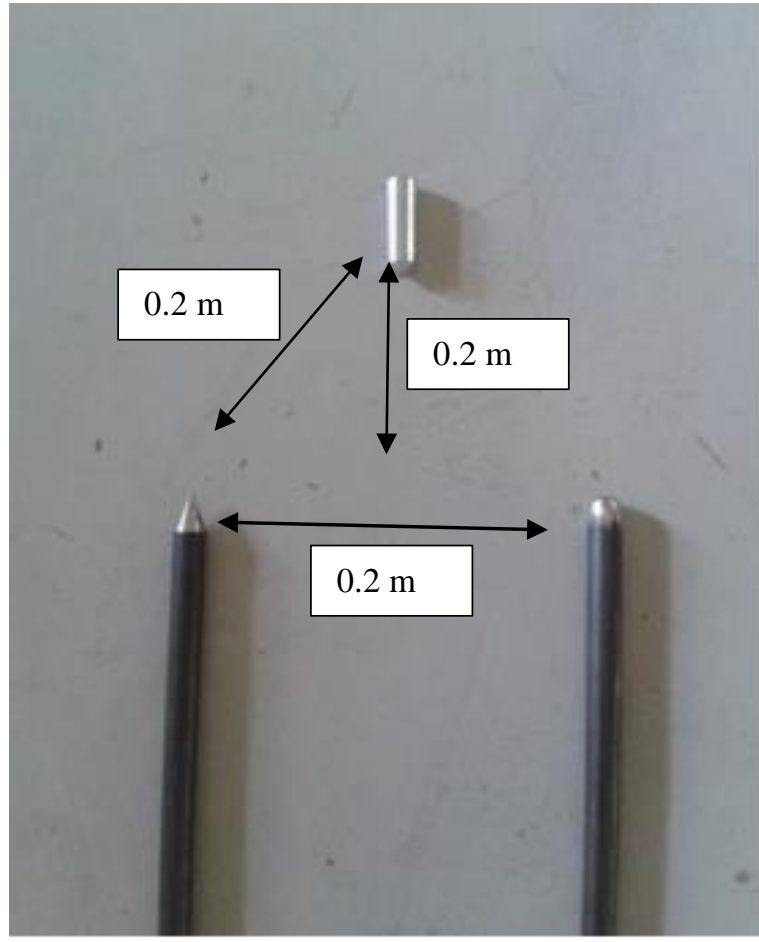

Figure 4. Experimental set up of competitive rod test

\subsection{Striking distance test}

The striking distance is determined based on the average potential gradient between the upward leader tip and the downward leader tip and is equal to or larger than the critical electric field of the streamer channels [14]. The main factor that determines the striking distance is the electric field distribution between the downward leader tip and the lightning rod. The electric field was found to be strongly dependent on the structure of the lightning rod [15]. For similar dimensions of lightning rod and conditions of air, the obtained striking distance may vary between different models due to the different conditions for the inception of upward leaders.

The objective of this test is to obtain the maximum striking distance of each type of lightning rod. A pair of similar types of lightning rod was arranged horizontally and $220 \mathrm{kV}$ was applied to every pair of lightning rod being tested with various distances (refer to Figure 5 where $\mathrm{Y}$ distance is varied until it reaches the maximum distance).

\section{RESULTS AND DISCUSSION}

\subsection{Breakdown voltage of individual lightning rod}

Data from the experiment is depicted in Figure 6 below. It can be seen that the blunt rod has the lowest breakdown voltage in comparison to sharp and flat lightning rod. Breakdown voltage for blunt rod varies between $199.1 \mathrm{kV}$ to $199.5 \mathrm{kV}$ with the average of $199.5 \mathrm{kV}$. For sharp rod, the breakdown voltage ranging between $204.8 \mathrm{kV}$ to 205.8 $\mathrm{kV}$ with the average value of $205.4 \mathrm{kV}$. Finally, flat rod breakdown voltage fluctuates from $202 \mathrm{kV}$ to $222.8 \mathrm{kV}$ and average at $218 \mathrm{kV}$.

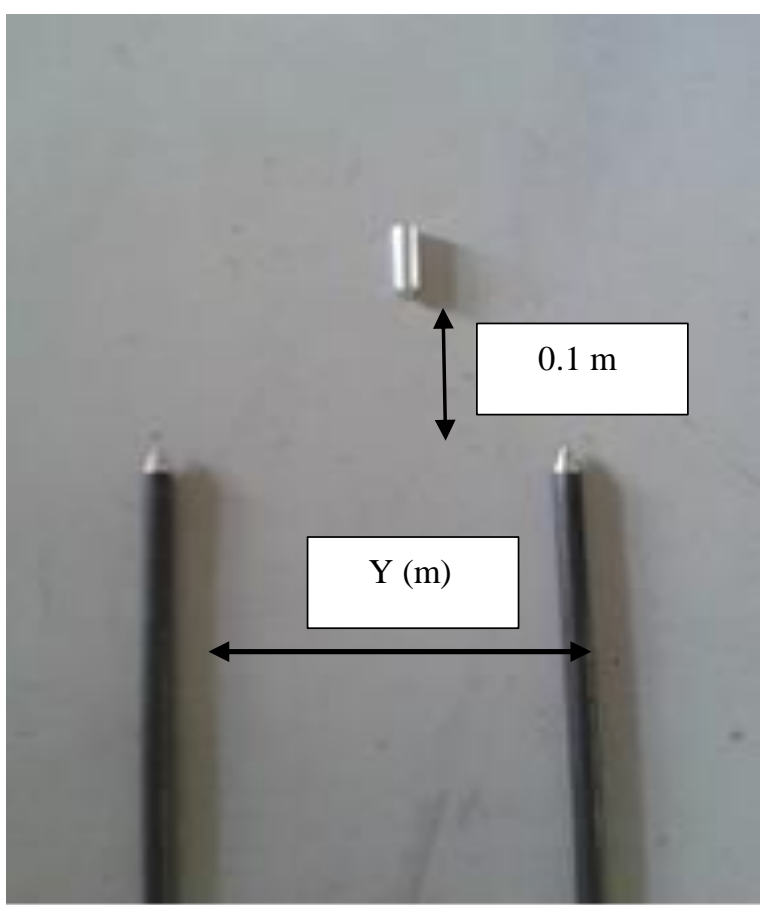

Figure 5. Experimental set up for striking distance test. Distance between two lightning rods, $\mathrm{Y}$ is varied until maximum distance is achieved.

Average breakdown Voltage for individual lightning rod

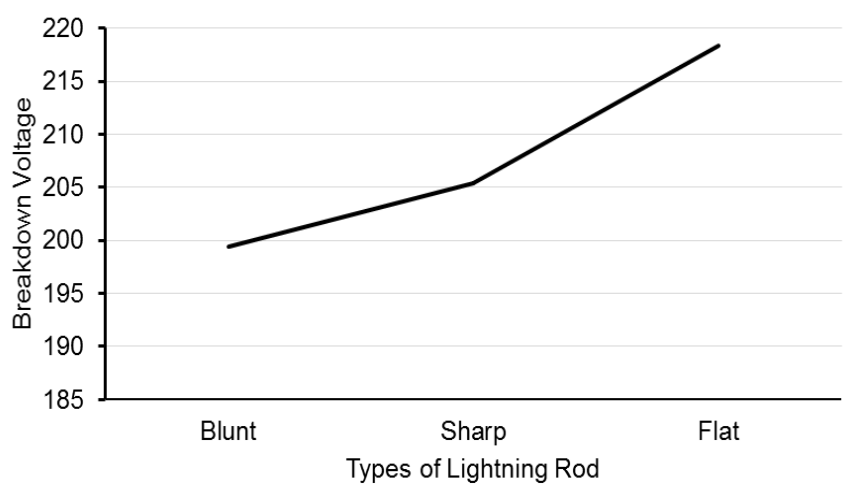

Figure 6. The average breakdown voltage of individual lightning rod.

\subsection{Competitive rod test}

Meanwhile, result for competitive rod test is tabulated in Table 1 below. Based on the result, it is observed that blunt rod has higher percentage of being strike compared to the sharp and flat rod. This result shows that the blunt rod had $60 \%$ of strikes while sharp rod suffers only $40 \%$ of strikes. For the sharp and flat rods, $70 \%$ of strikes went to sharp compared to flat which is only $30 \%$ of strikes. The last trial was between blunt and flat rod. About $70 \%$ of strikes went to the blunt rod while flat rod received only $30 \%$ of strikes.

\subsection{Striking distance test}

In Table 2, it can be clearly seen that blunt rod has the highest striking distance which is $25.5 \mathrm{~cm}$ to that of sharp and flat rod. The gap was varied from $0.1 \mathrm{~m}$ to $0.25 \mathrm{~m}$ in $0.05 \mathrm{~m}$ steps. The maximum striking distance recorded for 
sharp and flat rod are $24.6 \mathrm{~cm}$ and $23.7 \mathrm{~cm}$, respectively. The average breakdown voltage for the three recorded distances were approximately $213 \mathrm{kV}$. Referring to all the results of experiment conducted, blunt rod obtained the best result among all rod being tested based on its performance on voltage breakdown and the highest striking distance.

Table 1 Percentage of strike for various type of lightning rod

\begin{tabular}{c|lc}
\hline Types of Comparison & \multicolumn{2}{|c}{ \% of Strikes } \\
\hline \multirow{2}{*}{ Blunt and Flat } & Blunt & 70 \\
& Flat & 30 \\
\hline \multirow{2}{*}{ Sharp and Flat } & Sharp & 70 \\
& Flat & 30 \\
\hline \multirow{2}{*}{ Blunt and Sharp } & Blunt & 60 \\
& Sharp & 40 \\
\hline
\end{tabular}

Table 2 Striking distance result of different type of lightning rod

\begin{tabular}{lcc}
\hline $\begin{array}{c}\text { Types } \\
\text { of Rod }\end{array}$ & $\begin{array}{c}\text { Maximum Striking } \\
\text { Distance }(\mathbf{m})\end{array}$ & $\begin{array}{c}\text { Voltage } \\
\text { Breakdown } \\
(\mathbf{k V})\end{array}$ \\
\hline Blunt & 0.25 & 211.5 \\
Sharp & 0.24 & 216.3 \\
Flat & 0.23 & 213.0 \\
\hline
\end{tabular}

From the three results obtained, it is clearly shown that the blunt rod has better performance than flat rod and the widely used sharp rod. These experiment results are compatible with the previous studies [16, 17 and 15], where blunt rod has been found as the best rod with the minimum voltage breakdown compared to flat and sharp rod. Very strong electric fields occurred at the top of the rod and the value increases as the leader approaches [6]. The interception of lightning leader to the blunt rod at the lower voltage breakdown encouraged by the increases of electric fields energy. In their experiment to compare the performance of a sharp and blunt rod, they found that the blunt rod attracts more lightning leader attachment than its competitor [18]. It is happening due to the minimum prestroke space charge accumulation around the rod that enhances ability to initiate and sustain an upward leader [18]. In the competitive testing rod, the blunt rod has higher percentage of strikes while the sharp become second and flat has the lowest percentage of strikes. This blunt rod is exposed to intensifying electric field compared to both sharp and flat rod. Therefore blunt rod becomes the preferred point of interception. The limit of point discharge that built up at the sharp rod is the reason sharp rod is less preferred than the blunt rod.

\section{CONCLUSION}

From this experimental work, it is clearly proven that blunt rod can be the best strike receptor among other conventional lightning rod like sharp and flat rod. The blunt lightning rod has lower voltage breakdown and received more percentage of strikes compared to the sharp and flat rod. Further, it is also confirmed that blunt rod achieved highest distance of lightning strike in comparison to flat and sharp rods. Therefore, to avoid damages cause by lightning strike, it is suggested that the widely used conventional sharp rod to be replaced by the blunt rod.

\section{ACKNOWLEDGMENT}

This research is fully supported by FRGS grant, 04672, GUP grant 13H96 and Flagship grant 03G67. The authors fully acknowledged Ministry of Higher Education (MOHE) and Universiti Teknologi Malaysia for the approved fund which makes this important research viable and effective.

\section{REFERENCES}

[1] Donald W. Zipse,'Lightning Protection System: Advantages and Disadvantages," IEEE Trans. Ind. Appl, vol. 30, Oct.5, 1994.

[2] Jernegan, M. W. "Benjamin Franklin's "Electrical Kite" and Lightning Rod". The New England Quarterly (The New England Quarterly) 1 (2): 180 196, 1928.

[3] Copper lightning protection systems save lives, billions; Building and Architectural News, \#80, 1995.

[4] Ya-peng Fu, Cheng Gao and Bo Yang, 'The effect of metal layer surround the lightning rod on lightning electromagnetic field distribution' in Proc. of 7th Asia Pacific International Symposium on Electromagnetic Compatibility I, pp. 1156 - 1159, 2016.

[5] C.B. Moore, William Rison, James Mathis and Graydon Aulich,"Lightning Rod Improvement Studies," vol.39, May, 2000.

[6] C.B. Moore, William Rison and Graydon Aulich,"The Case for Using Blunt-Tipped Lightning Rods as Strike Receptors,"vol.42, July, 2003.

[7] William Rison, C.B. Moore and G.D. Aulich,"Lightning Air Terminal-Is Shape Important," in Proc. of IEEE International Symposium on Electromagnetic Compatibility, vol. $1,2004$.

[8] M. M. F. Saba, A. R. Paiva, C. Schumann, M. A. S. Ferro, K. P. Naccarato, J. C. O. Silva, F. V. C. Siqueira, D. M. Custódio, 'Lightning attachment process to common buildings', Geophysical Research Letters, Volume 44, Issue 9 , Pages 4368 4375, 2017.

[9] Young-ki Chung, Kang-soo Lee, Bok-hee Lee , 'Effect of the Corona Shield of the OMNI Bipolar Conventional Air Terminals' in Prof. of 14th International Conference \& Workshop on Electromagnetic Interference and Compatibility, 2016.

[10] Joon-Ho Lee, Young-Ki Chung, Hee-Ro Kwak and Il Han Park, "Local Electric Field Analysis for Evaluation of Charge Transfer System Using Sequential Subwindow Technique", IEEE trans. On Magnetics, vol.40, No.2, March 2004.

[11] Myung Ki Baek, Young Ki Chung, and Il Han Park,"Experiment and Analysis for Effect of Floating Conductor on Electric Discharge 
Characteristic", IEEE trans. On Magnetics, vol.49, No.5, May 2013.

[12] Se Hee Lee, Se Yeon Lee, Young-Ki Chung, and Il Han Park, "Finite-Element Analysis of Corona Discharge Onset in Air With Artificial Diffusion Scheme and Under Fowler Nordheim Electron Emission", IEEE Trans. Magnetics, vol.43, No.4, April 2007.

[13] Young-ki Chung, Kang-soo Lee, Bok-hee Lee, "Analysis and Test on Electric Field Concentration Effect of Bipolar Conventional Air Terminal”, 2014 International Conference on Lightning Protection (ICLP), October 2014.

[14] V. Cooray, V. Rakov and N. Theethayi, 'The lightning striking distance -Revisited', Journal of Electrostatics, 65, pp. 296 - 306, 2007.

[15] Ab Halim Abu Bakar, Alyaa Zainal Abidin, Hazlee Azil Illias, Hazlie Mokhlis, Syahirah Abd. Halim,
Nor Hidayah Nor Hassan, Chia Kwang Tan, 'Determination of the striking distance of a lightning rod using finite element analysis', Turkish Journal of Electrical Engineering and Computer Sciences, vol. 24: 4083 - 4097, 2016

[16] Lai Mun Ong and Hussein Ahmad,"Perfomance of Different Geometrical Tip of Conventional Lightning Air Terminals,'Universiti Teknologi Malaysia, 2003.

[17] Muhammad Abu Bakar Sidik, 'Lightning Air Terminal Enhancement Based On Charge Generation'. Ph.D. Thesis. Universiti Teknologi Malaysia, 2008.

[18] Alessandro, F.D. and Berger, G. Laboratory studies of corona emissions from air terminals. J. Phys. D: Appl. Phy. 32: 2785-2790, 1999. 